\title{
Development of a Web Based Environmental Health Tracking System for Nigeria
}

\author{
Adebayo P. Idowu \\ Department of Computer Science \& Engineering, Obafemi Awolowo University, Ile-Ife, Nigeria \\ paidowu@oauife.edu.ng \\ Emmanuel R. Adagunodo \\ Department of Computer Science \& Engineering, Obafemi Awolowo University, Ile-Ife, Nigeria \\ eadagun@ oauife.edu.ng \\ Olapeju A. Esimai \\ Department of Community Health, Obafemi Awolowo University, Ile-Ife, Nigeria \\ pejuesimai@yahoo.com
}

\begin{abstract}
This paper is to address the problem of environmental health monitoring system facing Nigeria as a whole. Environment and the factors that are associated with it are the root causes of many epidemic diseases both in the developed and developing nations. In Nigeria, environmental health problems arise from population pressure on housing, poor environmental sanitation, coupled with lack of safe drink water and basic housing facilities. Despite the deplorable state of environmental health (lack of clean and safe drinking water, bad housing condition, and so on), there is no reliable and timely means of surveillance or any monitoring system. The result of this research makes it possible for environmental health workers to capture environmental health situation of any house in Nigeria real time while on the field. In conclusion, this paper presents result of a research which developed a web based environmental health tracking system for Nigeria.
\end{abstract}

Index Terms - Environmental Health, Real-time, Ttracking System, Environmental Health Related Disease

\section{Introduction}

Environment is central to continued existence on earth and changes in the environment (both natural and man made) has either negative or positive impact on man. The relationship between man and the environment is a complex web of interactions with casual and consequential interrelationships ${ }^{[1]}$. The environment and the factors that are associated with it are the root causes of many epidemic diseases both in the developed and developing nations ${ }^{[2][3]}$.

In Sub-Saharan Africa (SSA), most public health problems are as a result of environmental problems such as poor housing condition, inadequate sanitation, insufficient or contaminated water, and smoky cooking fuels ${ }^{[4]}$. Epidemic diseases have highly destructive effects around the world and these diseases have affected both developed and developing nations. While the developed nations are taking adequate steps to address the environmental health related problems, most developing nations are yet to understand the magnitude of the impact of the problem ${ }^{[5][6]}$.

In developing nations, poor water supply, poor sanitation and hygiene tend to account for a large part of the burden of illness and death. About 4 billion cases of diarrhea per year cause an estimated 2.2 million deaths with majority of causalities being children under the age of five ${ }^{[7]}$. In addition, diarrhea also accounts for $4.3 \%$ of the total global disease burden and an estimated $88 \%$ of this burden is attributable to unsafe drinking water supply, inadequate sanitation and poor hygiene. Three hundred million people are estimated to suffer from malaria ${ }^{[8]}$.

In Nigeria, environmental health problems arise from or are compounded by population explosion pressure on housing, lack of facilities and basic services such as water and sanitation, electricity and poor environmental sanitation ${ }^{[6]}$. On potable water supply, it has been observed that in many SSA nations, the women and children, who are traditionally carriers of wood and fetchers of water, spend more than half of their working days in quest of water ${ }^{[9]}$. These sources are almost invariably polluted and contaminated with human and animal wastes giving rise to high incidence of waterborne and water related diseases which cause death to the young and kill or cripple the adults ${ }^{[9]}$.

Clean water, and proper sanitation are the keys to good health and eradication of diseases in SSA region most especially Nigeria ${ }^{[10]}$. If a proper surveillance system can be in place, which can be used to monitor clean and safe drinking water and general sanitation, the money expended on environment related diseases will greatly reduce. In addition, most of the environmental related diseases in Nigeria, which are caused by bad 
housing condition, eating or drinking contaminated water or foods cannot be prevented by vaccines but through the use of efficient and effective surveillance or tracking system.

At present, there is no country within SSA region with any electronic environmental health database or a reliable and efficient method of environmental health tracking system. In addition, the region is currently faced with the challenge of limited number of environmental health officers to address the problems of the region and even from the available ones; many still migrate to North America and Europe ${ }^{[11]}$. The absence of a system that can collect real-time environmental and sanitation data and lack of a reliable national environmental health tracking system, coupled with limited number of environmental health officers, has led to increase in the challenges of environmental problems and the control of environment related diseases in Nigeria.

In order to efficiently and effectively monitor the state of environmental health of any community in Nigeria, there is the need for a reliable national environmental health database and a national environmental health tracking system. In order to solve this problem of inconsistent, incomplete, inadequate and untimely environmental health data, this research aims to develop a web-based spatial environmental health tracking system with inbuilt predictive capacity. This system would be used in the monitoring and controlling of environmental health related problems, which would eventually reduce or eliminate environmental health related diseases in Nigeria

The remainder of this paper is organized as follows: Section 2 presents the review of environmental health in developed nations and Africa most especially in Nigeria. Section 3 describes different existing environmental heath tracking systems. Section 4, 5 and 6 present method used, system architecture and use case diagram of the EHTS respectively. Section 7 and 8 discusses the EHTS. Conclusion is given in the final section.

\section{Literature Review}

\section{A. Environmental Health}

Environmental health, which is also known as environmental public health, deals with the human health and diseases that are determined by the factors in the environment ${ }^{[12]}$. It encompasses the assessment and control of those environmental factors that can potentially affect health. It is targeted towards preventing disease and creating health-supportive environments. The World Health Organization (WHO) defines environmental health as "theory and practice of assessing and controlling factors in the environment that can potentially affect health." The WHO also stated: "Environmental health is comprised of those aspects of human health and disease that are determined by factors in the environment" ${ }^{[13]}$.
Environmental health is the health consequences of interactions between human populations and the whole range of natural, built and social environmental factors. It addresses air pollution (indoor and outdoor), body art (permanent cosmetics), climate change, disaster preparedness, food safety, housing (housing abatement, inspection of prisons, and so on), safe drinking water, noise pollution, waste management among other things.

Basically, environmental health has two major components namely: biophysical and built environment. Biophysical environment deals with air pollution, water, land and food, while the built environment deals with offices, homes, roads, and so on. This research will address safe drinking water, and house conditions because these are part of the most prominent environmental problem affecting the study area and Nigeria as a whole.

\section{B. Environmental Health in Developed Nation}

Environment in which people live is one of the determinants which not only provides necessary life resources, but which also is a source of multiple health hazards. The environmental health problem starts from the air we breathe, the food we eat, the water we drink and the beds we sleep in. According to a recent report by the World Health Organization ${ }^{[14]}$ nearly one quarter of all deaths and of the total disease burden globally can be attributed to the environment. In addition, environmental risk factors play a role in more than $80 \%$ of the burden of disease measured by the World Health Organization ${ }^{[15]}$. Most developed nations such as America, Canada and European Union are still battling with environmental related problem though at a reduced rate when compared with developing nations.

According to the World Health Organization, at least 3 million children die each year from causes related to the environment. Most of these deaths are caused by diarrhea and result from poor sanitation and water quality. Most of the remaining cases are caused by malaria, an infectious disease resulting from an environment that supports the breeding and proliferation of the mosquito vector. Beyond these fatal cases, $40 \%$ of the global burden of environmental disease falls on the world's 2.3 billion children ${ }^{[16]}$.

In 2004, the World Health Organization published the Atlas of Children's Environmental Health and the Environment ${ }^{[17]}$. This valuable resource maps the distribution of environmental health problems on a large scale. It vividly demonstrates that there are two world regimes as far as the health of children are concerned. In developed nations, the most common environmental health problems are air pollution, vehicular injury, pesticide exposure and lead toxicity ${ }^{[18][19]}$.

\section{Environmental Health in Africa}

Environment plays an important role in human development and health. Researchers have linked 
exposures to some environmental hazards with specific diseases. About one quarter of the global disease burden and one third of that in developing nations could be reduced through available environmental health surveillance, interventions and strategies ${ }^{[3]}$.

Unsafe drinking water, indoor and outdoor air pollution, unhygienic or unsafe food, poor sanitation, inadequate refuse disposal, absent or unsafe vector control and exposure to chemical and injuries have been identified as key environmental risks to human health in SSA ${ }^{[20]}$. An estimated 24 percent of the global disease burden and 23 percent of all deaths can be attributed to environmental factors. Of the 102 major diseases, and injuries covered by the World Health Report in 2004, environmental risk factors contributed to disease burden in 85 categories. The specific fraction of disease attributable to the environment varied widely across different disease conditions.

Also 25 percent of all deaths in developing nations were attributable to environmental causes, while only 17 percent of deaths were attributed to such causes in the developed world ${ }^{[21]}$ and Figure 1 depicts the global environmental related disease burden. In 2002 alone, 23 percent of all deaths in Africa were attributed to environmental risks factors ${ }^{[21]}$. In the same year 2002, 1.03 million deaths in Africa were linked to inadequate water supply, sanitation and hygiene. Also, 0.55 million deaths were attributed to unsafe drinking water ${ }^{[13]}$ and 0.040 million deaths were related to air pollution ${ }^{[22]}$.

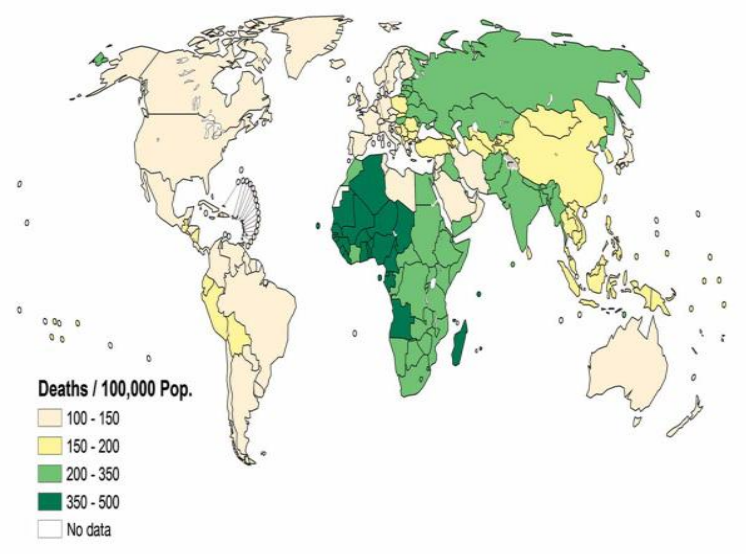

Fig 1 Global environmental related disease burden

\section{Environmental Health in Nigeria}

Environment is the totality of all external conditions and influences to which an organism is subjected. On the other hand, health, according to the World Health Organization, is said to be a state of complete physical, mental and social well-being and not merely the absence of disease or infirmity. However, a healthy environment is essential to the well-being of the planets and the productivity of its inhabitants, who depend solely on it for the air they breathe in, the water they drink, as well as the food they eat ${ }^{[23]}$.
The public worldwide has now become acutely aware that health and life sustainability are put at risk with the present level of poor sanitary conditions of the environment. Some of the waste dumped around proved extremely toxic and hazardous, which through their indiscriminate dumping, have brought about the death of livestock, environmental pollutions, and an increasing number of incidents that have caused illhealth and epidemic of diseases, which in some cases have led to loss of human lives. A potentially more serious risk of human health is the contamination of source of water supply ${ }^{[24]}$.

These problems become more peculiar in Nigeria where policy for physical development and developmental control are merely on paper without being implemented ${ }^{[25]}$. Also, the inadequate sanitary, unsafe drinking water and lack of refuse disposal facilities and congestion of buildings and people are common features in Nigeria. Environmental health problems are one of the major causes of death and illness in developing nations and this problem affects both children and adults ${ }^{[26]}$. Generally, environment related diseases are transmitted through the ingestion of water and food that are contaminated by faecal materials that carry infective dose of various pathogens.

In addition, according to USAID in 2011, environmental health problems are largely caused by unsafe water, inadequate sanitation and poor hygiene among human population in developing nations and Nigeria inclusive ${ }^{[26]}$. Environment related diseases like diarrhoea, gastro-enteritis, malaria, measles, cholera and typhoid are prevalent in Nigeria and these are mostly cause by unsafe drinking water, poor housing quality, lack of refuse disposal and poor sanitation.

In Nigeria, many researchers had conducted survey on the state of environmental health related problems (such as housing quality, type of available bathroom and toilet facilities in Nigeria), though they could not give a conclusive useful means of addressing the problems ${ }^{[6][27][28]}$. The research intends to develop a spatial tracking system for environmental health in Nigeria to monitor the problems identified above in order to prevent and control environmental health problems. The state of water supply, housing, in Nigeria are discussed below.

Access to safe drinking water and improved sanitation is essential for healthy life and can significantly reduce public expenditure on preventable diseases and epidemics arising from contaminated drinking water and unhygienic disposal of human waste ${ }^{[22]}$. Water supply is one of the most essential resources that support the existence of both animals and plants. It plays a key role in the metabolic breakdown of essential elements in protein and carbohydrates. Also, the blood in human and sap in plants largely consists of water. Well water and the one from street vendors are not fit for drinking and these are the major sources of the water commonly found in Nigeria. 
In urban areas, the potential risk of waterborne disease transmission can be increased by deficient sewage disposal, inadequate housing, precarious water supply and sanitation infrastructure, as well as poor water-related and hygienic practices ${ }^{[29][30]}$. Although the relationship between water quality and health is evident, yet in Nigeria, reliable and safe drinking water is scarce. There are different sources of drinking water in Nigeria and Table 1 below gives the summary of the sources of water in Nigeria. In addition, according to Oguntoke in 2009, 77 percent of Nigerians drink well water, while only 2.3 percent use tap water. So, this is an indication that over $70 \%$ of Nigerians are vulnerable to water borne diseases ${ }^{[27]}$.

Table 1: Sources of water supply in Nigeria

\begin{tabular}{|l|l|}
\hline \multicolumn{1}{|c|}{ Sources } & \multicolumn{1}{c|}{ Percentage } \\
\hline Well/Water Street Vendors & 77 \\
\hline Borehole & 19 \\
\hline Stream & 1.1 \\
\hline Tap & 2.3 \\
\hline Others & 0.3 \\
\hline
\end{tabular}

Source: Oguntoke et al, 2009

Also, some studies have showed that there is a relationship between incidences of disease and epidemics and housing quality ${ }^{[31][32]}$. In Nigeria, housing quality survey was conducted, in the study, the housing quality survey (HQS) form was used to capture basic deficiencies with respect to water supply, means of sewage disposal, toilet facilities, bathing facilities, electricity supply, ventilation facilities, safety, susceptibility to weather and degree of occupancy. The study showed that about $72 \%$ of the houses surveyed are classified as unfit for human habitation ${ }^{[33]}$. It also showed that over $70 \%$ of Nigerians are living in an unfit accommodation, and since quality of housing is a function of diseases; this implies that over $70 \%$ of Nigerians are prone to environment related diseases due to poor housing conditions.

The sanitary facilities in Nigeria are inadequate; this obviously indicates the socio- economic condition of the majority of Nigerians. Poor housing and sanitation have contributed to increase of measles incidence ${ }^{[34]}$. Sanitation will be based on the condition of the toilet, and bathroom. The sanitation condition is too poor and often times some state governments force people to forcefully carry out sanitation on monthly basis.

In Nigeria, very little attention is given to the provision of quality toilet and bathrooms facilities. According to the study carried out by Owoeye in 2005 in Akure, Southwestern Nigeria, about $58.2 \%$ of buildings examined have bathroom within the building, out of which only $4.3 \%$ are self-contained, while $53.9 \%$ shared this facility thereby making them to be over utilized. About $3.7 \%$ have theirs outdoors made with ordinary bamboo or rusted iron-sheets; some of which are inconveniently located at the backyard or between two houses. On kitchen facilities, only $5.2 \%$ were self contained, $63 \%$ were shared, while $3.5 \%$ do not have any. In order to monitor the state of environmental health in any location ${ }^{[35]}$ within Nigeria, this research developed a web based environmental health tracking system in which the environmental health officer can capture any environmental health information real-time.

\section{Existing Environmental Health Tracking System}

There is quite a number of existing environmental health tracking systems (EHTS). The leading among the systems are those developed for the United States, Canada and Europe. Others include the one used for air pollution in Japan, the epidemiologic surveillance system implemented in the Hautes-Alpes district in France, and the one used during the winter Olympic games in Torino.

Despite the fact that developing nations, most especially nations within SSA region are characterized with environment related diseases there is almost no existing environmental health surveillance system in any of the nations. The existing EHTSs are discussed in the next section based on their scopes, strengths and limitations.

\section{A. CDC Environmental Health Tracking System}

In January 2001, the Pew Environmental Health Commission called for the creation of a coordinated public health system to prevent diseases in the United States by tracking and combating environmental health threats. In response, the U.S. Congress appropriated funds to the Centers for Disease Control and Prevention (CDC) in 2002. This funding enabled CDC to develop the National Environmental Health Tracking Program [36]

Its report ${ }^{[37]}$ was a first attempt at defining the scope of the tracking system. The commission identified a lack of critical knowledge in environmental public health, the so-called environmental health gap. It recommended the establishment of a National Environmental Health Tracking Program, which was launched in 2002, as a program within the Centers for Disease Control. This was in concert with the Environmental Protection Agency, the National Aeronautics and Space Administration and state partners ${ }^{[38]}$. The goal of the program is to allow the federal, state and local governments to "monitor and distribute information about environmental hazards and disease trends; to advance research on possible linkages between environmental hazards and disease, and to develop, implement and evaluate regulatory and public health actions to prevent or control environment-related diseases" [39].

The aim of CDC EHTS is to provide information from a nationwide network of integrated health and environmental data that drives actions to improve the 
health of communities. The system is expected to (1) provide timely and consistent information for stakeholders; (2) provide access to and ability to integrate local, state, and national databases of environmental hazards, environmental exposures, and health effects; (3) enable broad analysis across geographic and political boundaries; (4) promote interoperable systems through compliance with standards; (5) increase environmental health capacity at the state and local levels; (6) provide the ability to enhance and improve data; and (7) provide a secure, reliable, and expandable ability to link environmental and health data ${ }^{[40]}$.

\section{B. European Union Environmental Health Tracking System}

The European Community Health and Environment Information System project (ECOEHIS), conducted under the leadership of the WHO-European Centre for Environment and Health has developed environmental health indicators as part of the European Community Health Indicators, which would serve as tools to aid in the following:

i. to measure the health impact of selected environmental risk factors; their determinants and trends therein, throughout the community;

ii. to facilitate planning, monitoring and evaluation of community programs and actions and;

iii. to provide member states and international organizations with information to make comparisons and evaluate their policies ${ }^{[41]}$.

The core set of environmental health indicators has been developed within the strength of the system and includes upstream driving forces; home, work and ambient exposures; population exposure; and health impact assessment (air quality, noise); linked to healthbased policy; action programs and developing a children's environment and health indicator set. The weaknesses of the system are under development, and lack of forecasting capacity.

\section{Quebec Environmental Health Tracking System}

In the state of Quebec, the Ministry of Health and Social Services has established a surveillance system regarding environmental hazards, occupational health and infectious diseases. In Quebec, a common surveillance plan, including environmental health, occupational health and infectious diseases, was established under the Ministère de la santé et des services sociaux (MSSS), and is centralized within the Public Health Institute. Indicators are chosen by expert consensus in accordance with the Public Health Program objectives, 2003-2012 (MSSS 2003). Currently, 26 of the 41 environmental health indicators are reported, 17 related to exposures and nine with health data ${ }^{[42]}$.
While these three systems differ in terms of stage of development and comprehensiveness, they point to the recognition that environmental health in the public domain requires more attention to protect the health of populations. The strengths of the system are: Common surveillance with occupational and infectious diseases within Ministry of Health and Social Services; annual reporting; research in environmental health surveillance; and strong public health surveillance mandate in 2001 Public Health Law. The weaknesses of the system are under development of the system, lack of forecasting capacity, potable water and housing quality features.

\section{France Epidemiologic Surveillance System for Winter Olympic Games}

This epidemiologic surveillance system was set up by the local health authorities. The goals were to detect in a timely fashion any phenomenon which could justify prevention or sanitary control action, and to guide interventions in the case of outbreak or environmental pollution. The system was implemented from January $30^{\text {th }}$ to March $15^{\text {th }}, 2006$.

A sentinel network of general practitioners was set up, and was used to report the frequency of acute gastroenteritis, influenza-like illness and measles. Statutory notification diseases and toxic effects of carbon monoxide surveillances were reinforced ${ }^{[43]}$. An integrated epidemiological surveillance and response system, set up by the regional and national Italian health authorities during the Games, had as its goal the early detection of any adverse health events particularly clusters of communicable diseases ${ }^{[44]}$.

The overall aim of the system was to address air pollution and food safety during the Winter Olympic Games, Torino 2006. The strengths of the system are: to detect in a timely fashion any phenomenon, which could justify prevention or sanitary control action; to guide interventions in the case of outbreak or environmental pollution; tracking of morality; the early detection of any adverse health events during games and monitoring of hygiene conditions of restaurants. The systems weakness is its inability to forecast environmental health related disease. Although the system was developed to monitor and prevent diseases during the then winter Olympic game and the system did not address potable water and housing quality ${ }^{[43]}$ issues.

\section{E. Environmental Health Surveillance System in Japan Air Pollution and Children's Health}

1986 was a turning point of air pollution policy in Japan. The Compensation Law for Pollution-Related Health Damage, which started in 1973, was revised because of the changes in pollution's character ${ }^{[1]}$.

Environmental health surveillance system is composed of two monitoring systems; environment monitoring and health monitoring, and the special committee on data management and analysis. The 
system was to evaluate the air pollution levels in the study area by small districts within distance of 1 kilometer radius with interpolation method using the air pollution data at monitoring stations in and around the study area. Nitrogen dioxides, nitrogen oxides, sulphur dioxides and suspended particulate matter (SPM) were used as pollution indices. The system's aim is to analyze the relationship between the prevalence of asthma and the air pollution level ${ }^{[1]}$.

However, all these existing tracking systems lack relevant features such as housing quality (such as ventilation, sanitation, overcrowding), water quality (such as potable water), refuse disposal and ability to forecast environment related diseases, which are the focus of this research.

\section{Method}

This research adopted the descriptive and exploratory designs that allowed the collection of data from sub-set of a population whose analyses can be generalised on the entire population. The adoption of these methods also gave a multi faceted articulation on the different aspects of the study. The research randomly selects some states in Nigeria as a study area namely; Ekiti, Lagos Ogun, Ondo, Osun, and Oyo.

In order to achieve the objectives of this research, the researcher personally observed environmental health conditions in all the selected states used in this research in order to assess their environmental health facilities conditions and problems. In addition, data on environmental health from the environmental health, water and sanitation departments of the selected states within Nigeria were collected through structured and unstructured personal interview. Some of the forms used in the water and sanitation departments were also collected which was used as a guide in order to develop the environmental health tracking system (EHTS).

In order to develop the EHTS, environmental health database was developed using MySQL. In the process of developing environmental health database, different tables, files, records and fields were created. Also, different environmental health conditions on water quality, housing conditions such as toilet, refuse disposal unit, etc, which were gathered from the study areas, were stored in the database. The MySQL in wampserver was used to create and populate the database. The EHTS was implemented using dream weaver, and PHP. Apache was used as the server to provide basic functionality of the web GIS. PHP was used as a scripting language to program the server side that manipulates the knowledge in the database. Geospatial web based environmental health tracking system was implemented on the EHTS system architecture.

\section{System Architecture}

In the design of any system related to the EHTS, there is a need for system architecture. In the environmental health tracking system, there is a need to make the design of the system easy, flexible and portable as much as possible. This allows users to be able to make use of portable computer system, desktop computer system, and mobile phone as web browser to access the proposed system. In this research, clientserver system architecture is used and it is thin clientserver. The environmental public health tracking system has two components namely: the server-side and clientside that run on the browser.

The system was modelled using the client-server architecture. In the client approach almost all the processing work was done on demand at the server end and the client task was to display data and information on the screen. In the client in thin client-server architecture, the web browser is the client. This research used this architecture because with it users will not be required to install any software on their systems expect a standard web browser, which often come, with most computer operating system and almost all the current standard mobile phone.

Clients would also not require any powerful computer systems; users can use any computer with a web browser such as laptop/notebook, mobile phone, and desktop computer systems. The servers would require higher configuration (in terms of hardware) computer system because it would be regularly subjected to heavy load. They would be HTTP server, database server and webGIS server. Figure 2 below depicts the environmental public health tracking system architecture.

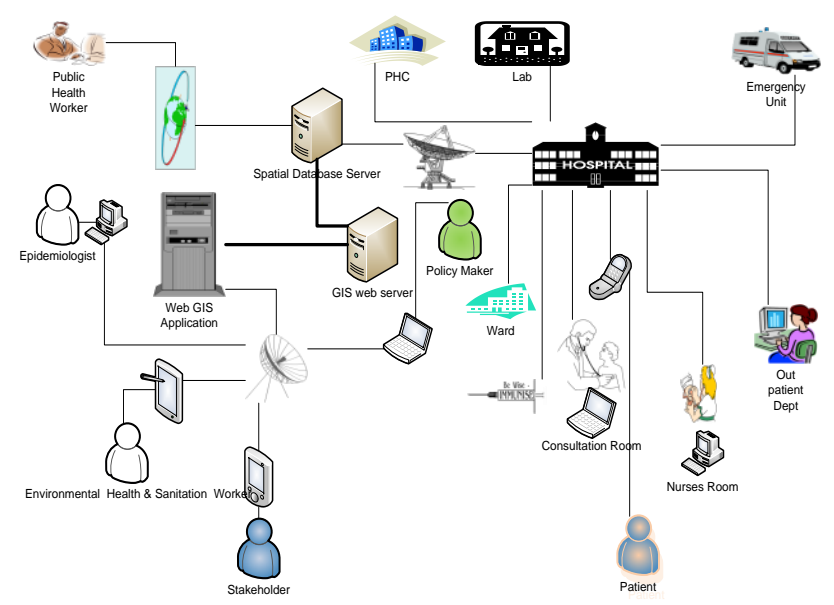

Fig 2: The proposed system architecture for the environmental health tracking system (EHTS)

\section{Used Case Diagram for EHTS}

The use case diagram is used in presenting the system requirements of any proposed system. A use case is a realistic description of the workflow of the system and 
it is used to explicitly describe the intentions and actions of users ${ }^{[45]}$. The use case diagram, which present the system requirements are used to show how the proposed system work in practice. The interaction between actor and use cases are also described using use case diagram. The use case diagrams of the proposed environmental health tracking system are as presented in figures 3 and 4 below.

The use case diagrams show how data will be entered and viewed from the proposed environmental health tracking system. Environmental health officers would be able to view the environmental condition of any location and predict the likelihood of any environmental health related diseases. Also, the environmental health officers would be able to enter all environmental health data of the entire streets in the specified location into the health information system or national public health database. The online monitoring and tracking of environmental health status of all locations in Nigeria would also be possible. As a result, the proposed system is capable of monitoring diseases that are paramount in a particular area.

Policy makers would also be able to view the environmental health state of any state, local government area, city/town, ward and street in the study area. International organizations and non-governmental organizations will also be able to view the state of environmental health of any location in the study area and channel any health assistance to the appropriate location.

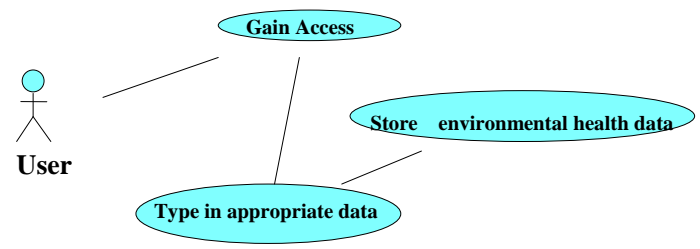

Fig 3: use case diagram showing data insertion in the proposed environmental health tracking system

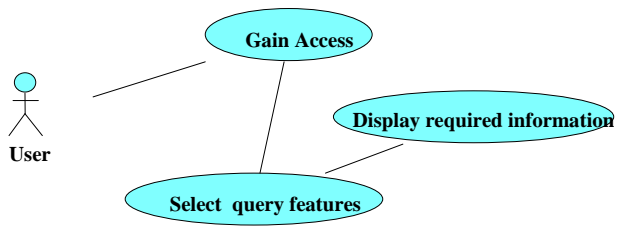

Fig 4: The use case diagram showing query feature in the proposed environmental public tracking system

\section{Implementation of the EHTS}

\section{A. User Interface Design}

The user interface allows the user to navigate the proposed system and communicate with the database. The system design is simple enough for use by anyone with little knowledge of computing and since the targeted end users are staff of environmental health and sanitation department of local government area in the study area, the system is user friendly and made easy to use through the use of windows, interface menu and pointing devices (WIMP) which is very important in computer graphics design and architecture. After the user gets to the EHTS website, the system will allows the user to select from the map a particular state of interest and the select the local government. Figure 5 depicted the user interface of the EHTS.

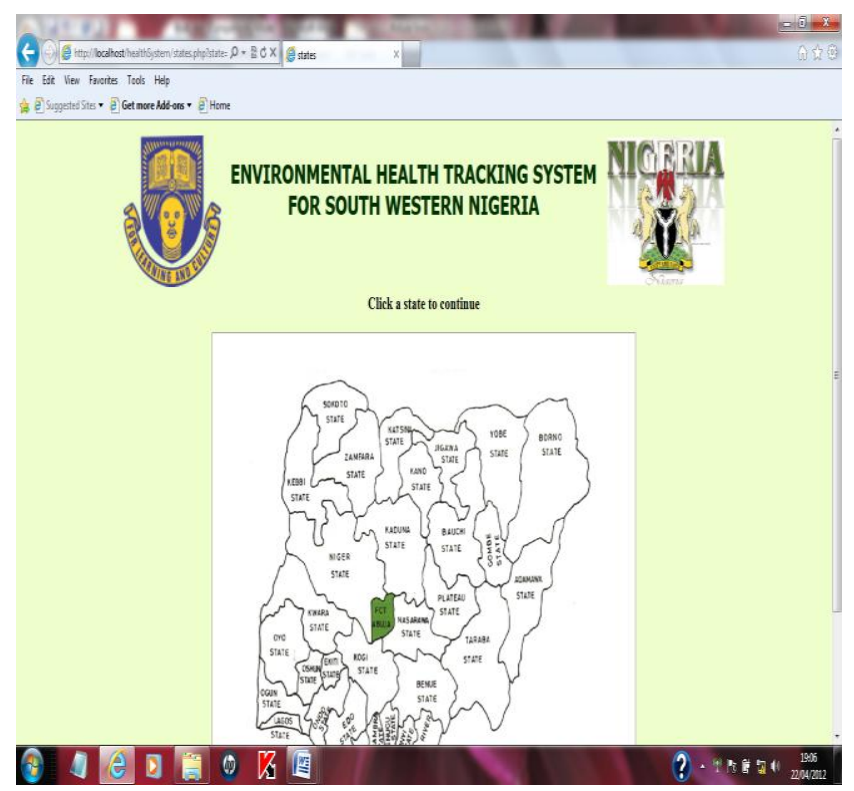

Fig 5: The user interface of the EHTS.

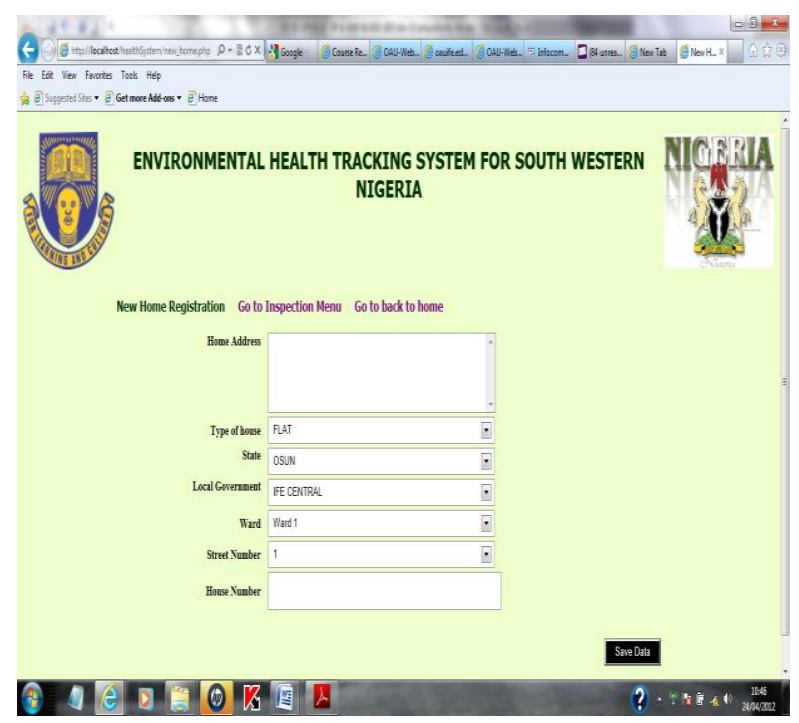

Fig 6 House Registration Menu

\section{B. Home Registration Menu}

This menu allows the environmental health officer to register the house under inspection in the EHTS, the officer will select the ward, street and house number. This will allow for proper document of the house. This house registration is done once and consequently the environmental health officer does not need to register the house again. This menu allows user to modify, store and delete any house from the house registration menu. Figure 6 depicts house registration menu. 


\section{Inspection Menu}

This menu holds, types of house, water, toilet, refuse facility and general sanitation. Under the water, it stores information about the state of water and type of water (that is pipe borne, bore hole, well, stream, etc) in the specified location. It provides real time data reporting, editing and query functions of the water unit. In the menu, toilet facility stores information about the toilet condition of the house of the specified location. It holds information about the type of toilet (such as VIP, water closest and pit) available in the specified location. It provides real time data reporting, editing and query functions of the toilet facility available in any location. The inspection menu also allows general comments on each of the variables in the menu. This menu is depicted in figure 7 .

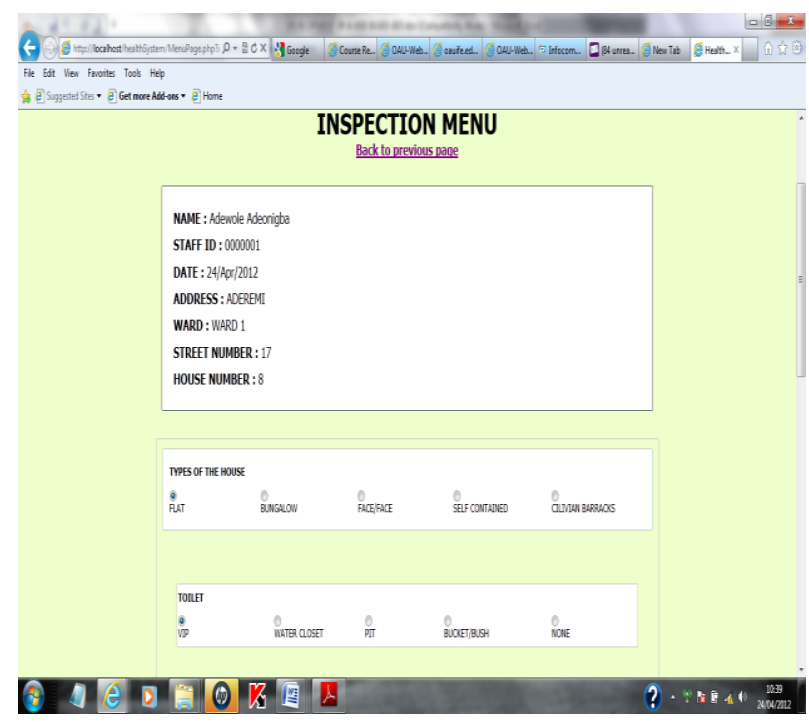

Fig 7: Inspection Menu

\section{Discussion}

With the environmental health tracking system, the environmental health officers would be able to type in the environmental health conditions such as type of water, type of toilet facilities, and availability of refuse disposal facilities and general sanitation of the specific location. The environmental health data such as availability of toilet, refuse disposal facilities, etc would be store real-time while on the field. The supervisor in the office can assess the work done by the subordinate before the arrival. In addition, all the information can serve as a guide for the health policy maker to make useful decision.

In the data reporting and editing of the developed system, the system handles over eighty data fields that are divided into sections. In addition, many data validation rules have been implemented. Users can create new records in water, refuse disposal and toilet facilities modules, edit existing records or search specific records based on the location or environmental health officer codes. Any authorized users would be able to go online and view environmental health condition of any desired location. Users also can predict likelihood of environmental health disease in any location online.

This system demonstrates that web based system may enhance environmental health system in two ways. One is to enhance tracking data management and this is achieved by editing, reporting, deleting environmental health data. The other is to enhance tracking information services, such as the provision of a query, generation of reports, among others.

\section{Conclusion}

In conclusion, this research presents an environmental health tracking system for Nigeria. The EHTS developed is not a complex system because the EHTS was developed to allow environmental health officers to be able to capture environmental condition of any location while on the field and immediately the information is being stored into the tracking system, other environmental health officers can work on the information, make useful decision. Also, the policy makers and other stakeholders can view the environmental health condition of any location realtime.

In addition, query based on housing condition such as toilet, refuse disposal facility, among other things are possible with this tracking system. The tracking system that was developed is flexible, expandable and allows interoperability. With this system users would be able to know the water condition of any location as well as housing condition. The tracking system would allow prediction of occurrence of environmental health related diseases in any location within the study area. The stakeholders would be able to visualize the distribution of different types of water and this would eventually aid decision making. In addition, the tracking system would also allow users to be able to query and visualize the environmental health condition of any house within the application area.

The environmental health tracking system developed in this research is not without limitations. The tracking system only covers water, and housing conditions and environmental health diseases that are caused by water and housing conditions.

\section{References}

[1] Ono, $\mathrm{M}^{*}$; Honda, $\mathrm{Y} \dagger$; Moriguchi, $\mathrm{Y}^{*}$; Odajima, H†; Ohara, T*; Shima, M§; \& Tanaka, T (2006). Environmental Health Surveillance System in Japan Air Pollution and Children's Health. Epidemiology: 17(6), pp 262-263

[2] $\mathrm{WHO}(2009)$ : Meningococcal in Nigeria. Available from: http://www.who.int/csr/don/2009_02_19/en/index. html [Accessed May 7, 2010] 
[3] WHO(2010). Children's environmental health. Available from: http://www.who.int/ceh/en/index.html [Accessed 10 March, 2011]

[4] Bashir SA. 2002. Home is where the harm is: inadequate housing as a public health crisis. American Journal of Public Health 92(5):337738.

[5] Alan Abelsohn, John Frank and John Eyles (2009). Environmental Public Health Tracking/Surveillance in Canada: A Commentary. Healthcare Policy, 4(3): 37-52

[6] Adeboyejo, A. T. Abolade, O. \& Oshinowo, T. (2009). The Prevalence of Environmental Related Diseases in Peri-Urban Area of Ogbomoso, Nigeria. Ethiopian Journal of Environmental Studies and Management. 2(2)::73-83

[7] Pokhrel Damodar and Viraraghavan Thiruvenkatachari (2004). Diarrhoeal diseases in Nepal vis-a` -vis water supply and sanitation status, Journal of Water and Health 2(2): 71-81

[8] Onwuliri O.E(2010). Environmental Health and Climate Change in Nigeria, an invited lectured delivered at the 2010 Annual Public Lecture \& Award Ceremony of the Society for nvironmental Health of Nigeria held in Collaboration with the Environmental Health Officers Registration Council of Nigeria at the Rock View Hotel, Abuja On 31st Of August, 2010.

[9] World Bank(2007). Growth, Poverty and Inequality

[10] Paulson Tom (2001). A breakdown of our primary health care system, Seattle Post-Intelligence. Available from: http://www.seattlepi.com/africa/nigeria22.shtml [Accessed 2 March, 2011]

[11] Gelan Mengistu Kifle (2006). A Theoretical Model for Telemedicine : Social and Value Outcomes in Sub-Saharan Africa. Unpublished $\mathrm{PhD}$ dissertation submitted to the Institutionen för data- och systemvetenskap, Stockholms Universitet

[12] Centers for Disease Prevention and Control (2006). National Environmental Public Health Tracking Program. "Background." Available from: www.cdc.gov/NCEH/Tracking/background.htm [Accessed 12 Januray,2011]

[13] WHO(2008). Safe Water Better health, Costs and benefits and Sustainaility of Interventions to Protect and Promote Health. Pruss-Usten A, Boss R, Gore Bartram J., World Health Organization, Geneva.

[14] WHO(2006). Preventing Disease Through Healthy Environments: Towards an Estimate of the
Environmental Burden of Disease. Geneva: World Health Organization.

[15] WHO(2011a). Environment and health: Healthy environments for healthy people Available from: http://www.euro.who.int/en/what-we-do/healthtopics/environment-and-health [Accessed July 14, 2011]

[16] Commission for Economic Cooperation(2006). Children's health and the environment: a first report on available indicators and measures. Geneva: World Health Organization.

[17] Gordon B, Mackay R, and Rehfuess E (2004). Inheriting the world: the atlas of children's health and the environment. Geneva: World Health Organization.

[18] Cox RD, Kolb JC, Galli RL, et a(2005)1. Evaluation of potential adverse health effects resulting from chronic domestic exposure to the organophosphate insecticide methyl parathion. Clin Toxicol, 43:243-53.

[19] WHO(2011). Water and sanitation: Clean and safe water combats ill health Available from: http://www.euro.who.int/en/what-we-do/healthtopics/environment-and-health/water-andsanitation [Accessed July 14, 2011]

[20] WHO/UNEP(2008). Traditional and Current Environmental Risks to Human Health. First InterMinisterial Conference on Health and Conference in Africa, Health security through Healthy Environments. IMCHE/1/CP1

[21] WHO(2006). Preventing Disease through Healthy Environment: Towards an Estimate of Environmental Burden of Disease. Pruss-Usten A and Corvalan C, World Health Organization, Geneva.

[22] WHO (2007). Updated and Air Quality Guidelines, Microsoft Corporation. Available from: www.euro.who.int/air/activities/20050222_2 [Accessed 04March 2011].

[23] WHO / UNEP (1996): Pollution and Health; World Health Publication, Geneva. World Commission of Environment and Development (1998): Our Common Future. Oxford University Press, Oxford.

[24] Adeola F. O (1996): “Environmental Hazards, Health and Racial Inequality in Hazardous Waste Distribution”. Environmental Behaviour . 26, Pp 99.

[25] Omole F.K. (2003): Urban Renewal Theory and Practice: Some Lessons from Nigeria. International Journal of Environmental Issues. 1 (1): $115-123$ 
[26] USAID(2011). Safeguarding the World's Water. 2011 Report on USAID Fiscal Year 2010 Water Sector Activities. July 2011.

[27] Oguntoke, O. Aboderin O. J. \&. Bankole, A. M (2009). Association of Water Borne Diseases Morbidility Pattern and Water Quality in Parts of Ibadan City, Nigeria. Tanzania Journal of Health Research. 11(4). Pp189-195.

[28] Ayodele, J. T. \& Abubakar, F. (2009). Sulphur dioxide as Indoor Pollutant in Kano Municipality kano Nigeria. Journal of Environmental Chemistry and Ecotoxicology. 2(1):9-13

[29] Brick T, Primrose B, Chandrasekhar R, Roy S, Muliyil J, \& Kang G(2004). Water Contamination in Urban South India: Household Storage Practices and their implications for Water Safety and Enteric Infections. International Journal of Hygiene Environmental Health; 207:473-80.

[30] Cifuentes E, Mazari-Hiriart M, Ferreira F, Bianchi F, \& Gonzalez D(2002). The Risk of Enteric Diseases in Young Children and Environmental Indicators in Sentinel Areas of Mexico City. International Journal of Environmental Health Research; 12,pp.53-62.

[31] Sangodoyin A Y and Coker A O (2005). Case Study Evaluation of Health-Care Solid Waste and Pollution aspects in Ibadan, Nigeria. Journal of Applied Science, Engineering and Technology, 5(1): 27-32.

[32] Aluko M A O (2006). Illness: causes and their meaning among the Yoruba, In: Falola, T. and Heaton, M.M.(Eds). Traditional and Modern Health Systems in Nigeria, Africa World Press, Trenton, NJ, pp 399-410.

[33] Coker, A O, Awokola, O S Olomolaiye, P O and Booth C A ( 2007). Challenges of Urban Housing Quality and its Associations with Neighbourhood Environments: Insights and Experiences of Ibadan City, Nigeria. 7(1)

[34] Muruka C. and Muruka, A. (2007). Guidelines for Environmental Health Management in Children's Homes in Sub-Sahara Africa. International Journal of Environmental Research and Public Health. 4(4), pp.319-331

[35] Owoeye , J. O (2005) : Analysis of Slum Formation and Its Associated Effects on a Residential Core Area of Akure. An M. Tech. Post -Survey Seminar. Presented to the School of Environmental Technology, Federal University of Technology, Akure; December 8th.

[36] CDC(2006). CDC's National Environmental Public Health Tracking Program: National Network Implementation Plan (NNIP) Version 1.0, Available from: http://www.cdc.gov/nceh/tracking [Accessed 11 March, 2011]
[37] Pew Environmental Health Commission. (2000). "America's Environmental Health Gap: Why the Country Needs a Nationwide Health Tracking Network." Baltimore: Johns Hopkins School of Hygiene and Public Health, Department of Health Policy and Management. Available from: http://healthyamericans.org/reports/files/ healthgap.pdf [Accessed 12 January,2011]

[38] McGeehin, M.A., J.R. Qualters and A.S. Niskar.(2004). "National Environmental Health Tracking Program: Bridging the Information Gap." Environmental Health Perspectives 112(14):40913.

[39] CDC (2006): What is PulseNet. Available from http://www.cdc.gov/PULSENET/whatis.htm. [Accessed 8 Jan, 2011]

[40] CDC/EPHT(2006). CDC's National Environmental Public Health Tracking Program: National Network Implementation Plan (NNIP) Version 1.0. Available from: http://www.cdc.gov/nceh/tracking [Accessed 12 March, 2011]

[41] WHO(2004). Cholera in Nigeria. Globla Alert and Response. Available from http://www.who.int/csr/don/2004_12_03/en/index. html [Accessed 09 March, 2011]

[42] Comité d'éthique de santé publique du Québec(2004). "Avis du Comité d'éthique de santé publique. Projet de Plan commun de surveillance de l'état de santé de la population et de ses déterminants 2004-2007." Available from: http://msssa4.msss.gouv.qc.ca/fr/sujets/ ethiqSP.nsf/0/35570c61afcd975685256e ad00636ccc/\$FILE/AVIS_PCS.pdf > [Ac cessed December 31, 2010].

[43] Franke F, Coulon L, Renaudat C, Euillot B, Kessalis N, \& Malfait P.(2006). Epidemiologic Surveillance System Implemented in the HautesAlpes District, France, During the Winter Olympic Games, Torino 2006. Euro Surveill. 1(12): 671.

[44] Epidemiological Consultation Team(2006). Surveillance System in Place for the 2006 Winter Olympic Games, Torino, Italy, 2006. Euro Surveill 2006;11(2):E060209.4. Available from: http://www.eurosurveillance.org/ew/2006/060209. asp\#4[Accessed 2 March, 2011]

[45] Jacobson, I., Cristerson, M., Jonsson, P., Övergaard, G. (1992) : Object Oriented Software Engineering: A Use Case Driven Approach. MA: Addison-Wesley

Adebayo P. Idowu: $\mathrm{He}$ is a Lecturer at the Obafemi Awolowo University, Nigeria. He is also a Member of British Computer Society and Nigerian Computer Society. He authored many journal articles in Nigeria 
and abroad. His research interests include Software Engineering, Geographical Information System, Database Design, and Health Informatics. He enjoys reading and driving.

Emmauel R. Adagunodo: $\mathrm{He}$ is a Professor of Computer Science \& Engineering in Obafemi Awolowo University, Nigeria. He is presently Head of Computer Science \& Engineering, He is a Registered Member of Nigeria Computer Professional of Nigeria, and Nigerian Computer Society. He is an external examiner to many universities in Africa. He has supervised many Doctoral and Master Students. He is an author of many journal articles both within and abroad. His research interests include Software Engineering, and operating system.

Olapeju Esimai: Dr Esimai Olapeju Adefunke is an Associate Professor /Consultant in Department of Community Health Obafemi Awolowo University, Nigeria. She lectures both undergraduates and postgraduates students in Departments of Community Health, Medical Rehabilitation and Nursing the area of Reproductive Health, Epidemiology and Environmental. She is actively involved in researches in the area of Reproductive Health and Environmental Health. She is a Consultants to agencies like WHO, USAID , UNICEF, NACA. She was involved in the development of the health sector response of the multi-sectoral plan for HIV/AIDS and served as Health Impact Assessment Advisor in Shell Petroleum Development Company.

Her research interest include Epidemiology, International and Environmental Health and Reproductive Health. She authored many journal articles within and outside Nigeria. 